\title{
Transplante autólogo de conjuntiva em pterígio primário
}

\author{
Conjunctival autograft transplantation in primary pterygium
}

\author{
Aisa Haidar Lani ${ }^{1}$ \\ Luiz Alexandre Lani²
}

${ }^{1}$ Oftalmologista, Diretora da Clínica de Olhos Dr. Luiz Lani. Ex-Fellow da Universidade Federal de São Paulo UNIFESP.

${ }^{2}$ Oftalmologista, Diretor da Clínica de Olhos Dr. Luiz Lani. Ex-Fellow da Clínica Olhos Dr. Suel Abujamra.

Os autores não têm interesse comercial nas medicações.

Endereço para correspondência: Av. Afonso Pena, 4254 - Campo Grande (MS) - CEP 79020-001

E-mail: lani@pobox.com

Recebido para publicação em 26.03.2004

Versão revisada recebida em 11.08.2004

Aprovação em 30.08.2004

\begin{tabular}{|l|}
\hline RESUMO \\
\hline Objetivo: Avaliar a resposta ao tratamento da técnica do transplante \\
autólogo de conjuntiva em pterígios primários. Métodos: Estudoprospectivo \\
de 230 pacientes (230 olhos) com pterígio primário e que foram submetidos \\
a transplante autólogo de conjuntiva. O seguimento mínimo foi de 12 \\
meses. Resultados: Após o tratamento do pterígio primário com transplan- \\
te autólogo observou-se recidiva em 2,17\%, perda de enxerto em $0,43 \%$. \\
Conclusões: O transplante de conjuntiva é procedimento combaixoíndice \\
de complicações. Porém, os resultados da literatura estimulam novos \\
estudos clínicos prospectivos e randomizados para avaliarmos as respos- \\
tas do transplante autólogo de conjuntiva em comparação às demais \\
técnicas de abordagem cirúrgica do pterígio. \\
\hline
\end{tabular}

Descritores: Pterígio; Transplante autólogo; Conjuntiva/transplante

\section{INTRODUÇÃO}

Pterígio é o crescimento de tecido fibrovascular proveniente da conjuntiva bulbar, geralmente presente na região nasal da fissura interpalpebral, em direção à córnea ${ }^{(1)}$. É uma afecção de etiologia multifatorial, relacionada com a exposição à radiação solar, microtraumatismos de repetição, inflamações crônicas, idade, hereditariedade e distúrbios imunológicos ${ }^{(2)}$.

A remoção cirúrgica é a única conduta disponível até o momento para a completa resolução do pterígio e está indicada nos casos em que há prejuízo na acuidade visual, restrição da motilidade ocular, inflamações crônicas, sintomas irritativos persistentes, ou alterações cosméticas ${ }^{(3)}$.

Diferentes modalidades cirúrgicas existem para abordagem terapêutica do pterígio, dentre as quais destacam-se: excisão simples (esclera nua), excisão com rotação de retalho, excisão com ceratoplastia lamelar, transplante autólogo de conjuntiva e transplante de membrana amniótica ${ }^{(2-3)}$. A recidiva do tecido fibrovascular é o maior problema do tratamento cirúrgico do pterígio que chega até $89,8 \%$ para alguns procedimentos e tende às vezes a ser mais agressiva que a lesão primária ${ }^{(3-4)}$.

O transplante autólogo de conjuntiva foi considerado um método efetivo para reduzir as taxas de recidiva do pterígio a partir de 1985. Esta técnica consiste no enxerto de conjuntiva livre, obtido do quadrante súpero-temporal do mesmo olho, para recobrir a esclera exposta após a excisão da lesão. Foi observado por alguns autores a recorrência de 5,3\% em pterígios recidivados ou avançados ${ }^{(5)}$. Taxas maiores de recidivas foram no entanto, detectadas em áreas geográficas com maior exposição à radiação ultravioleta ${ }^{(6)}$.

O objetivo deste estudo é avaliar a resposta ao tratamento da técnica do transplante autólogo de conjuntiva em pterígios primários. 


\section{MÉTODOS}

Estudo prospectivo em 230 olhos de 230 pacientes que foram submetidos à técnica de transplante autólogo de conjuntiva por apresentarem pterígio primário, no período de junho de 1999 a março de 2004, com seguimento mínimo de 12 meses.

Os pacientes foram avaliados quanto à idade e sexo. Foram submetidos a exame oftalmológico que constituiu de: determinação da acuidade visual (AV), pressão ocular e exame biomicroscópio.

As lesões foram classificadas (Tabela I) à biomicroscopia:

1 - conforme sua extensão em relação ao limbo corneano e pupila em:

- grau I: lesões que atingiam até $1 \mathrm{~mm}$ do limbo;

- grau II: lesões que se estendiam além do limbo sem acometer a região pupilar;

- grau III: lesões que atingiam a pupila;

- grau IV: lesões que ultrapassavam a pupila.

2 - quanto à morfologia em carnosas e atróficas, baseadas na transparência do tecido fibrovascular;

- carnosas: quando o corpo era formado por tecido espesso que não possibilitava observação de vasos subjacentes, e

- atróficas: quando o corpo do pterígio permitia a observação dos vasos episclerais subjacentes ${ }^{(7)}$.

As cirurgias foram realizadas sempre pelo mesmo cirurgião (LAL), seguindo-se as mesmas técnicas de anti-sepsia e com a seguinte técnica operatória: anestesia tópica com cloridrato de proximetacaína $0,5 \%$, com olhar direcionado de forma a expor o campo cirúrgico; delaminação da cabeça da lesão com bisturi lâmina 15 até o limbo e remoção da cabeça juntamente com o tecido fibrovascular adjacente; cauterização minimizada, procurando preservar a vascularização do leito do enxerto; medida da área receptora com compasso cirúrgico, delaminação da área doadora no quadrante súpero-temporal; remoção do enxerto com tesoura de conjuntiva, excluindo-se a cápsula de Tenon; a conjuntiva foi transportada para o leito receptor, respeitandose a origem limbo/limbo da conjuntiva a ser transplantada com a área receptora; fixação do enxerto na área receptora por meio de pontos contínuos usando-se fio de nylon 10.0.

Ao final da cirurgia foi instilado colírio de cetorolaco de trometamina $\left(\right.$ Acular $\left.^{\circledR}\right)$ e pomada de tobramicina associado a dexametasona e realizado curativo oclusivo, mantido por 24 horas. No pós-operatório, utilizou-se curativo oclusivo com pomada de tobramicina por 3 dias seguidos de colírio de tobramicina associado a dexametasona quatro vezes ao dia por 1 semana sendo reduzido 1 gota a cada semana completando um período de 4 semanas.

Os pacientes foram avaliados no $1^{\circ}, 7^{\circ}, 15^{\circ}, 30^{\circ}, 60^{\circ}, 10^{\circ}$, $180^{\circ}$, e $365^{\circ}$ dias após a cirurgia quanto à presença de recidiva clínica, caracterizada por tecido fibroso e vascular atingindo a superfície corneana passando além do limbo ou presença de complicações.

Os dados foram submetidos à análise estatística, usando o teste de Goldman. O critério de inclusão foi pterígio primário e o critério de exclusão foram a presença de outras afecções oculares e perda de seguimento no período da avaliação.

\section{RESULTADOS}

Dos 230 pacientes estudados, 118 possuíam pterígio no olho direito e 112 no olho esquerdo. Destes, $46,95 \%$ eram masculinos e $53,04 \%$ femininos; $31,30 \%$ com idade entre 22 a 40 anos, $47,82 \%$ entre 41 a 60 anos, e $20,86 \%$ com mais de 61 anos (Tabela II). Não houve diferença estatisticamente significante entre os grupos de pacientes que apresentaram ou não recidiva clínica, com relação à idade $(p>0,05)$. Não se encontrou, também, diferença estatisticamente significativa quanto aos fatores sexo e olho acometido, entre os grupos de pacientes que apresentaram ou não recidiva do pterígio.

O exame oftalmológico revelava apenas a lesão conjuntival, sendo o restante dentro da normalidade inclusive a pressão ocular.

A amostra foi constituída predominantemente de pterígios atróficos $(76,95 \%)$ sendo a maioria $(58,26 \%)$ lesão GII.

No pós-operatório observou-se recidiva em 4 casos, $(2,17 \%)$ sendo 2 casos no período de 2 meses e 2 no período de 9 meses de acompanhamento. Observou-se também $1(0,43 \%)$ caso com perda de enxerto após 15 dias de acompanhamento.

\section{DISCUSSÃO}

O pterígio é uma afecção que causa uma morbidade visual importante no Brasil e nos países tropicais e equatoriais do mundo ${ }^{(8)}$. Estudos prévios mostram maior prevalência nos in-

\begin{tabular}{cccc|}
\hline \multirow{4}{*}{$\begin{array}{c}\text { Tabela II. Características dos pacientes com pterígios primários } \\
\text { submetidos a transplante autólogo de conjuntiva }\end{array}$} \\
\multirow{4}{*}{ Olho } & Variável & Número de pacientes & $\%$ \\
& Direito & 118 & 51,30 \\
Sexo & Esquerdo & 112 & 48,69 \\
& Masculino & 108 & 46,95 \\
Faixa etária & Feminino & 122 & 53,04 \\
& $22-40$ anos & 72 & 31,30 \\
& $41-60$ anos & 110 & 47,82 \\
& $>60$ anos & 48 & 20,86 \\
\hline
\end{tabular}


divíduos expostos à radiação ultravioleta e a raridade de ocorrência nos menores de 15 anos $^{(2)}$.

$\mathrm{Na}$ amostra em estudo observou-se uma predominância de pterígios atróficos GII, quando o corpo do pterígio permitia a observação dos vasos episclerais subjacentes e as lesões se estendiam além do limbo sem acometer a região pupilar. Assim como Stern et al a remoção cirúrgica foi indicada quando havia prejuízo na acuidade visual onde o astigmatismo e opacificação do eixo visual são causas freqüentes. A restrição da motilidade ocular, inflamações crônicas, sintomas irritativos persistentes ou alterações cosméticas também foram indicações para a remoção cirúrgica ${ }^{(3)}$.

As técnicas disponíveis para o tratamento do pterígio devem ser avaliadas segundo dois critérios: segurança (ausência de complicações que comprometam a visão) e eficácia (ausência de recidiva).

No presente estudo, as complicações decorrentes do transplante autólogo de conjuntiva foram infreqüente. Granuloma da Tenon, cisto conjuntival e infecção não foram observados.

Comparamos no quadro I as taxas de recidivas após transplante autólogo de conjuntiva segundo autor, localidade e tipo de amostragem do estudo.

Entre os pterígios primários foi descrita taxa de recidiva de $6,8 \%$, com apenas 1 caso de recidiva ${ }^{(9)}$.

Em outro estudo a taxa de recidiva foi de $4,16 \%$ em portadores de pterígio primário e recorrente, sendo a recidiva observada entre os portadores de pterígios já recidivados ${ }^{(10)}$.

Num relato de 41 casos de pacientes com pterígios tratados com transplante autólogo de conjuntiva (33 primários e 8 recidivados), 3 (7,3\%) recidivaram. Destes 3 casos, 2 fizeram pelo menos duas exéreses simples anteriormente e $1(3,03 \%)$ era primário ${ }^{(11)}$.

Estudos randomizados mostraram resultados discordantes, quando comparados às técnicas de "esclera nua" e transplante de conjuntiva. A taxa de recidiva com a técnica de "esclera nua" foi de $61,0 \%$ contra $2,0 \%$ nos submetidos a transplante de conjuntiva ${ }^{(7)}$.

Em outro estudo não observaram nenhum caso de recidiva em portadores de pterígio primário e recidivado ${ }^{(12)}$.

O presente estudo apresentou uma taxa de recidiva de $2,17 \%$. O procedimento foi realizado pelo mesmo cirurgião, mesma técnica, com tamanho adequado de enxerto que são importantes para conter a recidiva. A taxa de recidiva pode ser influenciada por: fatores relacionados com a resposta do hospedeiro, a idade, as variações da técnica empregada, uso de terapia adjuvante, diferentes medicações utilizadas no pósoperatório, localização geográficas da população estudada, a duração do período de seguimento e pela definição de recorrência empregada ${ }^{(12)}$.

Outros autores observaram uma taxa de recidiva elevada $(41,6 \%)$ no tratamento de pterígios recidivados por transplante autólogo de conjuntiva ${ }^{(13)}$. Isto, pode ser compreendido devido à correção cirúrgica ser realizada em pterígios com maiores chances de recidiva, ou seja, recidivados e por serem realizadas por cirurgiões em formação, o que pode influenciar no resultado do tratamento, uma vez que a técnica cirúrgica e o tamanho adequado do enxerto são importantes para conter a recidiva.

Utilizaram também fio absorvível trançado que promove mais inflamação que os fios de monofilamentos atraindo neoformação vascular e consequentemente a recidiva ${ }^{(13)}$.

Os resultados da literatura com relação à taxa de recidiva estimulam novos estudos clínicos prospectivos e randomizados para avaliarmos as respostas do transplante autólogo de conjuntiva sobre as demais técnicas de abordagem cirúrgica do pterígio.

\section{CONCLUSÃO}

O transplante de conjuntiva é um procedimento com baixo índice de complicações. Porém, os resultados da literatura estimulam novos estudos clínicos prospectivos e randomizados para avaliarmos as respostas do transplante autólogo de conjuntiva sobre as demais técnicas de abordagem cirúrgica do pterígio.

\section{ABSTRACT}

Purpose: To evaluate the use of conjunctival autograft transplantation in the treatment of primary pterygium. Methods: Prospective study of 230 patients (230 eyes), with primary pterygium, who underwent conjunctival autograft as a treatment option for recurrent pterygium. The minimal follow-up was 12 months. Results: We observed a recurrency rate of $2.17 \%, 0.43 \%$ had loss of graft. Conclusion: Conjunctival

\begin{tabular}{|c|c|c|c|c|}
\hline Autor & Local & Tipo de estudo & Número de casos & Taxa de recidiva \\
\hline Allan et al, 1993 & Austrália & Retrospectivo & 93 & $6,80 \% \quad P P$ \\
\hline Cunha et al, 1993 & Brasil & Prospectivo & 24 & $4,16 \%$ \\
\hline Garcia et al, 1994 & Brasil & Retrospectivo & 70 & $0 \%$ \\
\hline Tan et al, 1997 & Singapura & Prospectivo & 61 & $2,00 \%$ \\
\hline Barbosa et al, 2002 & Brasil & Retrospectivo & 33 & $3,03 \%$ \\
\hline *Estudo, 2004 & Brasil & Prospectivo & 230 & $2,17 \%$ \\
\hline
\end{tabular}


transplant is a procedure that rarely brings any complication. However, the literature on the results leads to new clinical and randomized, studies, in order to evaluate the responses of the conjunctival autograft transplant as related to the other surgical techniques for pterygium.

Keywords: Pterygium; Transplantation, autologous; Conjunctiva/transplantation

\section{REFER̂̂ECIAS}

1. Bubak K, Khater TT, Friedman NJ, Koch DD. Corneal topographic changes induced by excision of perilimbal lesions. Ophthalmic Surg Lasers. 1999;30 (6):458-64

2. Adamis AP, Starck T, Kenyon DR. The management of pterygium. Ophthalmol Clin North Am. 1990;3(4):611-23.

3. Stern GA, Lin A. Effect of pterygium excision on induced corneal topographic abnormalities. Córnea. 1998;17(1):23-7.

4. Sing G, Wilson MR, Foster Cs. Mitomycin eye drops as treatment for pterygium. Ophthalmology. 1988;95(6):813-21.
5. Kenyon KR, Wagnorer MD, Hettinger ME. Conjunctival autograft transplantation for advanced and recurrent pterygium. Ophthalmology. 1985;92(11): 1461-70.

6. Lewallen S. A randomized trial of conjunctival autografting for pterygium in the tropics. Ophthalmology. 1989;96(11):1612-4. Commented in: Ophthalmology. 1990;97(5):542-3.

7. Tan DT, Chee SP, Dear KB, Lim AS. Effect of pterygium morphology on pterygium recurrence in a controlled trial comparing conjunctival autografting with bare sclera excision. Arch Ophthalmol 1997;115(10):1235-40. Erratum in: Arch Ophthalmol. 1998;116(4):552.

8. Pavilack MA, Halpern BL. Corneal topografic changes induced by pterygium. J Refractive Surg. 1995;11(2):92-5.

9. Allan BD, Short P, Crawford GJ, Barret GD, Constable IJ. Pterygium excision with conjunctival autografting: an effective and safe technique. $\mathrm{Br} \mathrm{J}$ Ophthalmol. 1993;77(11):698-701. Commented in: Br J Ophthalmol. 1994;78(5):421.

10. Cunha M, Allemann N. Transplante autólogo de conjuntiva no tratamento de pterígio primário e recidivado. Arq Bras Oftalmol. 1993;56(2):78-81.

11. Barbosa KH, Barbosa PH, Poli LT, Moreira H, Oliveira C. Resultados do transplante autólogo de conjuntiva em pterígio num estudo de 41 casos do Hospital de Olhos do Paraná. Arq Bras Oftalmol. 2002;65(Supl 4):7-64.

12. Garcia SG, Alleoni S, Junqueira AM, Rezende R. Técnica de enxerto autólogo de conjuntiva em pterigiectomia primária e recidivada. Rev Bras Oftalmol. 1994;53(4):33-6.

13. Samaha JT, Schellini AS, Sakamoto RH, Padovani CR. Tratamento do pterígio recidivado por transplante autólogo de conjuntiva. Arq Bras Oftalmol. 2002;65(4):415-8. 